\title{
sciendo
}

\section{Knee Forces During Landing in Men and Women}

\author{
by \\ Daniel J Cleather ${ }^{1}$, Maike B Czasche ${ }^{1}$
}

\begin{abstract}
Sex differences in biomechanics may provide one explanation for the greater incidence of knee injuries in women, but few studies have compared internal forces. In this study, a musculoskeletal model was used to compare male and female, bilateral and unilateral landings based on motion capture and force plate data. Participants were classified as landing medially or laterally loaded based upon the mediolateral load share at the knee (bilateral: $p<0.001, \eta^{2}=0.452$; unilateral: $\left.p<0.001, \eta^{2}=0.444\right)$. Knee kinematics and ground reaction forces were not different between the two groups $\left(p>0.05, \eta^{2}=0.001-0.059\right)$, but there were differences in muscular recruitment. Landing strategy did not appear to be dependent on sex. However, for both medially and laterally loaded bilateral landings men had greater gluteal ( $\left.p=0.017, \eta^{2}=0.085\right)$ and hamstrings forces $\left(p<0.001, \eta^{2}=0.183\right)$, whereas women had greater quadriceps forces $\left(p=0.004, \eta^{2}=0.116\right)$. This study demonstrates an association between muscular recruitment and medially loaded landings. Landing strategy seems to be a function of skill not sex; however, within a particular landing strategy there may be sex differences in muscular activation that contribute to the difference in injury rates.
\end{abstract}

Key words: sex characteristics, knee injuries, anterior cruciate ligaments, mediolateral load share.

\section{Introduction}

Ruptures of the anterior cruciate ligament (ACL) are serious musculoskeletal injuries that often require surgical treatment and lengthy rehabilitation periods (Delay et al., 2001), and that increase the risk of osteoarthritis in later life (Lohmander et al., 2007; Louboutin et al., 2009; Roos, 2005). The incidence of ACL injuries in women is much greater than in men (Arendt and Dick, 1995; Prodromos et al., 2007). A number of gender differences have been suggested to be important in understanding the higher incidence of ACL injuries in women that span several different domains (f. ex. anatomical, biomechanical, hormonal) (Alentorn-Geli et al., 2009; Elliot et al., 2010; Hewett, 2000; Hughes and Watkins, 2006). However, as some of these differences are less modifiable than others it is probably most useful to focus on differences between the genders which can be changed, and that can then serve as the basis of effective interventions. For instance, it has been well established that women often exhibit different lower limb mechanics when performing common athletic tasks like landing or cutting (Decker et al., 2003; Malinzak et al., 2001; Nagano et al., 2007; Schmitz et al., 2007; Golas et al., 2017), and it is thought that these differences provide one explanation for the increased risk of ACL injury.

ACL injuries are relatively common during landing after a jump (Ferretti et al., 1992; Ristić et al., 2010; Shimokochi and Shultz, 2008). A number of kinetic and kinematic differences have been found between men and women during landing (although there is some degree of inconsistency within the literature in terms of the specific differences expected, Beaulieu and McLean, 2012). For instance, it has variously been suggested that there are differences in joint excursions (Fagenbaum and Darling, 2003; Ford et al., 2006; Kiriyama et al., 2008; Lephart et al., 2002), joint moments (Butler et al., 2013; Ford et al., 2010; Kernozek et al., 2005; Orishimo et al., 2014),

1 - Faculty of Sport, Health and Applied Sciences, St. Mary's University, Twickenham, UK. 
energy absorption (Decker et al., 2003; Norcross et al., 2013; Schmitz et al., 2007), ground reaction forces (Kernozek et al., 2005; Pappas et al., 2007; Schmitz et al., 2007) and muscular activity (de Britto et al., 2014; Gehring et al., 2009; Nagano et al., 2007; Urabe et al., 2005) between men and women and that these differences contribute to the increased risk of ACL injury in women.

When considering the differences in ACL injury risk between men and women, it is important to distinguish between gender- and sex-specific factors. In this context, sex-specific factors are those which can be attributed solely to biological differences, whereas gender-specific factors encompass a wider range of differences that include those created by socio-cultural pressures. With regard to landing mechanics, these gender-specific factors might include the fact that men have more practice executing the skill of landing, might have stronger lower extremities due to greater engagement in athletic activities, etc. (Bruton et al., 2013). For instance, Orishimo and colleagues (2014) found that for experienced dancers, there was no difference in the landing mechanics of men and women. They attributed this to the fact that both male and female dancers receive balance- and jump-specific training from a young age. Thus, it may be more prudent to attribute differences in ACL injury risk simply to the landing strategy adopted by an individual, rather than to their gender (Bruton et al., 2013). The increased incidence of ACL injuries in women would then be attributed to the fact that a greater proportion of women exhibit a risky landing strategy.

Most studies of ACL injury mechanisms are based upon the measurement of external kinematics and kinetics or use techniques like electromyography to give some indication as to the level of activation of the muscles. However, it is the forces experienced by the musculoskeletal system that are most important if the mechanism of injury is to be understood, and most previous studies have not sought to quantify the forces within the muscles, joints or ligaments themselves. This is principally because the direct measurement of such forces can be very challenging, requiring expensive and surgically invasive techniques (Erdemir et al., 2007; Fleming and Beynnon, 2004). This is the reason why biomechanists have sought to develop musculoskeletal models of the body which can provide predictions of muscle, joint and ligament forces based upon non-invasive measurements of movement (Buchanan et al., 2004; Damsgaard et al., 2006; D'Lima et al., 2012; Pandy, 2001).

We have previously described a publicly available model of the lower limb (FreeBody) that can be used to estimate muscle and joint contact forces based upon external measurements of movement (Cleather and Bull, 2015). In our recent work (Price et al., 2017) we have shown that FreeBody is particularly sensitive to differences in the mediolateral distribution of the tibiofemoral joint contact force (minimal detectable change of $4-7 \%)$. Using the same model we have also shown that after a strength training intervention, there is a lateral to medial shift of the tibiofemoral joint contact force (TFJ) experienced during drop landings (Czasche et al., 2018). Mediolateral load share, that is the proportion of the TFJ acting through the medial compartment of the tibiofemoral joint, may thus be an effective variable to use to discriminate between different landing strategies. The purpose of this study was therefore to use FreeBody to quantify the loading of the tibiofemoral joint during bilateral and unilateral landings and then use the mediolateral load share to discriminate between medially and laterally loaded landing strategies. The key aim was to explore the differences between men and women, and to provide some commentary as to whether these are sex or gender differences.

\section{Methods}

\section{Participants}

Fifty-one participants were recruited for this study (Table 1). All participants were healthy, right footed and had been free from lower limb injury for the previous 6 months. In order to observe a range of different landing strategies we recruited both recreationally active and athletic participants. The inclusion criteria for the recreational participants included the stipulation that they took part in recreational sporting activity less than 4 times per week and that they were not performing heavy resistance training. In contrast, the inclusion criteria for the athletic participants were that they were physically active and that they participated in sport more than 4 times a week including resistance training. Ethical approval for this study was obtained from the 
institutional review board of St Mary's University, and all participants provided informed written consent before taking part in the study. The study was conducted in accordance with the ethical standards of the Declaration of Helsinki.

\section{Measures}

Kinematic and kinetic data describing the performance of each landing were collected using motion capture and force plate technologies. Data collection was performed at two different sites. The kinematic data consisted of the time dependent history of the positions of 18 retroreflective markers placed on key anatomical landmarks of the pelvis and right lower limb, as measured by a Vicon motion capture system sampling at $200 \mathrm{~Hz}$ (site 1: 11 camera array, Vicon MX System, Vicon Motion Systems Ltd, Oxford, UK; site 2: 10 camera array, Vicon MX System). The anatomical landmarks used in this study (Figure 1) have been described in our previous work (Cleather and Bull, 2015) and were located using the guidelines of van Sint Jan (2005). The time history of the ground reaction force (GRF) was collected using force plate technology (site 1: Kistler 9287BA Plate, $600 \times 900$ mm, Kistler Instruments Ltd., Hampshire, UK; site 2: Kistler 9286B AMTI Plate, $400 \times 600 \mathrm{~mm}$ ). The force plate was synchronised with the Vicon system and data were collected at $200 \mathrm{~Hz}$ for the recreational women and at $1000 \mathrm{~Hz}$ and then down sampled to $200 \mathrm{~Hz}$ for the other participants.

\section{Design and Procedures}

Upon reporting for testing, participants first performed a standardised, supervised, $10 \mathrm{~min}$ dynamic warm up and briefly practiced the step off task (Czasche et al., 2018) followed by a 3-5 min rest period during which the retro-reflective markers were attached. Participants then performed the landing trials. They were asked to step forwards from a $30 \mathrm{~cm}$ platform placed 0.5 $\mathrm{cm}$ from the force plate and to land naturally with their right foot entirely on the force plate. In stepping forwards from the platform participants were asked to ensure that they dropped from the height of the platform by not jumping off the platform or stepping down. In addition, for the bilateral landings participants were asked to land in such a way that both feet touched the ground at the same time. No other instructions as to landing technique were given. Participants first performed at least 5 bilateral landings with a $60 \mathrm{~s}$ rest interval in between, then took a 2 min break, before performing at least 5 unilateral landings, again with a $60 \mathrm{~s}$ rest between each. Trials that were not conducted in accordance with the above instructions were repeated.

\section{Data Analysis}

The raw data collected in this study were analysed using FreeBody (Cleather and Bull, 2015), a publicly available musculoskeletal model of the lower limb in order to calculate muscle and joint contact forces. The development of FreeBody and its calculation procedures (Cleather et al., 2011a, 2011b; Cleather and Bull, 2010b, 2011a, 2015), the sensitivity of FreeBody to various key modelling assumptions (Cleather and Bull, 2010b, 2010a, 2011b; Southgate et al., 2012), its validity (Cleather and Bull, 2015; Ding et al., 2016) and its reliability (Price et al., 2017) have been previously described, and so in line with the journal's policy, are only briefly outlined here. Firstly, the kinematic data were filtered using a dual pass $5^{\text {th }}$ order Butterworth filter with a cut-off frequency of $10 \mathrm{~Hz}$ (the force data was not filtered in order to preserve the initial impact spike). Next, positions of the markers were used to specify the locations and orientations of five rigid bodies that represented the right lower limb and pelvis. The external kinematics of the observed movement could then be calculated from these data. The musculoskeletal geometry of the limb was described by scaling the data of Klein Horsman and colleagues (2007) to fit the dimensions of the subject. This in turn then allowed the moment arms and lines of action of 163 muscle elements and 14 ligament elements to be calculated for each frame. The external kinematics and kinetics (force plate data) could then be combined with the musculoskeletal geometry to write the equations of motion that governed the movement of the lower limb - this was an indeterminate problem comprising 22 equations and 193 unknowns. FreeBody took an optimization approach to solve these equations - that is, the solution that simultaneously minimised maximum muscle stress and ligament force relative to the failure limit of the ligaments was selected (Cleather and Bull, 2011a; Crowninshield and Brand, 1981; Raikova, 2009). In this study, the strength of the model (i.e. the maximum muscle forces) was scaled relative to the body mass of the participants (Table 1), but if the model was unable 
to find a solution under the above constraints, then the model was strengthened to try and find a solution. If there were frames within a trial for which a solution could not be found then the trial was not included in the analysis.

\section{Statistical Analysis}

All data series were normalised relative to time $(t)$, such that the time from initial ground contact until the peak in GRF represented a time period of 1 unit (for a limited number of trials the initial impact peak was the global maximum - in these cases the data were normalised relative to the second GRF peak). Each data series was then interpolated using a cubic spline in order to determine the values at intervals of 0.05 units. The individual trials for each subject and landing condition were combined by taking the mean value at each time interval in order to produce a mean curve for each data series.

Mediolateral load share at time $t=2$ was used to designate participants as either medially $(>0.5)$ or laterally $(<0.5)$ loaded. The data series for the medially and laterally loaded groups were then combined by taking the mean and standard deviation at each time interval. This allowed composite curves and 95\% confidence intervals to be plotted for each variable.

Peak values were found for the period $t=0.0$ - 0.5, as well as the values at $t=1$ and 2. Two repeated measures factorial MANOVA (time $\times$ landing strategy $\times$ gender) with Bonferroni adjusted post hoc $t$ tests were used to test for differences for the bilateral and unilateral landings with an alpha level of 0.05 set a priori. In addition, effect sizes were calculated using partial $\eta^{2}$. Statistical analysis was conducted using IBM SPSS Statistics (version 24; IBM, Armonk, NY).

\section{Results}

The data set reported in this paper consisted of 182 bilateral landings from 50 participants and 181 unilateral landings from 45 participants. A medially loaded landing pattern was more common during both bilateral (28 participants medially loaded versus 22 laterally loaded) and unilateral (35 versus 10) landings (Table 2). Participants who landed with a laterally loaded tibiofemoral joint during unilateral landings tended also to exhibit lateral loading during bilateral landings (Table 2).

There were no significant differences in knee kinematics (Figure 1) between medial and lateral groups (time $\times$ strategy interaction) for both bilateral (flexion: $p=0.244, \eta^{2}=0.030$; adduction: $p$ $=0.930, \eta^{2}=0.002$; external rotation: $p=0.952, \eta^{2}=$ 0.001 ) and unilateral landings (flexion: $p=0.889, \eta^{2}$ $=0.003$; adduction: $p=0.566, \eta^{2}=0.014$; external rotation: $\left.p=0.508, \eta^{2}=0.016\right)$. Similarly, there were no differences in GRF for bilateral $(p=0.155$, $\left.\eta^{2}=0.040\right)$ or unilateral landings $\left(p=0.084, \eta^{2}=\right.$ $0.059)$. In contrast there was a large significant difference in mediolateral load share for both landing conditions (Figure 2; bilateral: $p<0.001, \eta^{2}$ $=0.452$; unilateral: $\left.p<0.001, \eta^{2}=0.444\right)$. There were also significant differences in TFJ (bilateral: $p$ $=0.001, \eta^{2}=0.138$; unilateral: $p<0.001, \eta^{2}=0.272$ ), gluteal force (Figure 3; bilateral: $p=0.001, \eta^{2}=$ 0.162; unilateral: $\left.p=0.020, \eta^{2}=0.091\right)$, quadriceps force (bilateral: $p<0.001, \eta^{2}=0.191$; unilateral: $p=$ 0.029, $\left.\eta^{2}=0.083\right)$, biarticular hamstring force (bilateral: $p<0.001, \eta^{2}=0.406$; unilateral: $p<0.001$, $\eta^{2}=0.373$ ), triceps surae force (bilateral: $p=0.286$, $\eta^{2}=0.027$; unilateral: $\left.p=0.001, \eta^{2}=0.156\right)$ and adductor force (bilateral: $p=0.044, \eta^{2}=0.066$; unilateral: $\left.p<0.001, \eta^{2}=0.288\right)$.

In contrast, when comparing genders for each movement strategy (time $\times$ strategy $\times$ gender interaction) there were few differences. There were no differences in knee kinematics, GRF, TFJ, mediolateral load share, triceps surae force, adductor force for bilateral landings (Figure 4; $p=$ $\left.0.226-0.907, \eta^{2}=0.002-0.032\right)$ and no differences for any variables for unilateral landings ( $p=0.070$ - 0.0-7, $\left.\eta^{2}=0.002-0.063\right)$. During the bilateral landings, there was a moderate significant difference for gluteal force (Figure 5; $p=0.017, \eta^{2}=$ $0.085)$, quadriceps force $\left(p=0.004, \eta^{2}=0.116\right)$ and hamstring force $\left(p<0.001, \eta^{2}=0.183\right)$.

More differences were found when gender was compared independently of landing strategy (time $\times$ gender interaction). The women landed with greater knee flexion for both conditions (bilateral: $p<0.001, \eta^{2}=0.170$; unilateral: $p=0.002$, $\left.\eta^{2}=0.136\right)$ and a smaller GRF in the bilateral landings (bilateral: $p<0.001, \eta^{2}=0.168$; unilateral: $\left.p=0.166, \eta^{2}=0.043\right)$. There were also differences in mediolateral load share (bilateral: $p=0.106, \eta^{2}=$ 0.048; unilateral: $p<0.001, \eta^{2}=0.172$ ), quadriceps force (bilateral: $p=0.001, \eta^{2}=0.142$; unilateral: $p=$ $0.200, \eta^{2}=0.039$ ), triceps surae force (bilateral: $p=$ 0.013, $\eta^{2}=0.090$; unilateral: $p=0.001, \eta^{2}=0.159$ ) and adductor force (bilateral: $p=0.021, \eta^{2}=0.081$; 
unilateral: $\left.p=0.183, \eta^{2}=0.041\right)$. Similarly, there were clear qualitative differences between the four different groups that were originally recruited (Figure 6).

Table 1

Participants' characteristics ${ }^{*}=$ significant difference between men and women; $t=$ significant difference between athletic and recreational).

\begin{tabular}{lccccc}
\hline & $\mathrm{n}$ & Age (years) & Height $(\mathrm{m})$ & Mass $^{*}(\mathrm{~kg})$ & $\begin{array}{c}\text { Activity } \\
\text { (hrs/week) }\end{array}$ \\
\hline Men & & & & & \\
$\quad$ Athletic & 16 & $22.8 \pm 4.2$ & $1.81 \pm 0.05$ & $81.3 \pm 11.6$ & $12.8 \pm 4.9$ \\
$\quad$ Recreational & 7 & $24.4 \pm 3.7$ & $1.81 \pm 0.07$ & $82.5 \pm 14.4$ & $2.5 \pm 1.6$ \\
& & & & & \\
Women & & & & & \\
$\quad$ Athletic & 14 & $22.9 \pm 3.0$ & $1.68 \pm 0.06$ & $66.4 \pm 8.2$ & $12.4 \pm 4.0$ \\
$\quad$ Recreational & 14 & $22.2 \pm 2.9$ & $1.66 \pm 0.05$ & $62.7 \pm 7.5$ & $2.9 \pm 1.4$ \\
& & & & & \\
\hline
\end{tabular}

Table 2

Classification of participants by mediolateral loading at the tibiofemoral joint

$\left(^{*}=\right.$ participants were also laterally loaded during the bilateral landings;

$t=$ participant was also medially loaded during the bilateral landing; $\ddagger=2$ of the 3 participants were also laterally loaded during the bilateral landings).

\begin{tabular}{|c|c|c|c|c|}
\hline & \multicolumn{2}{|c|}{ Bilateral } & \multicolumn{2}{|c|}{ Unilateral } \\
\hline & Medial & Lateral & Medial & Lateral \\
\hline \multicolumn{5}{|l|}{ Men } \\
\hline Athletic & 14 & 2 & 13 & $2^{*}$ \\
\hline Recreational & 1 & 6 & $1 \dagger$ & $3^{*}$ \\
\hline All Men & 15 & 8 & 14 & 5 \\
\hline \multicolumn{5}{|l|}{ Women } \\
\hline Athletic & 8 & 6 & 10 & $2^{*}$ \\
\hline Recreational & 5 & 8 & 11 & $3 \ddagger$ \\
\hline All Women & 13 & 14 & 21 & 5 \\
\hline All Participants & 29 & 22 & 35 & 10 \\
\hline
\end{tabular}




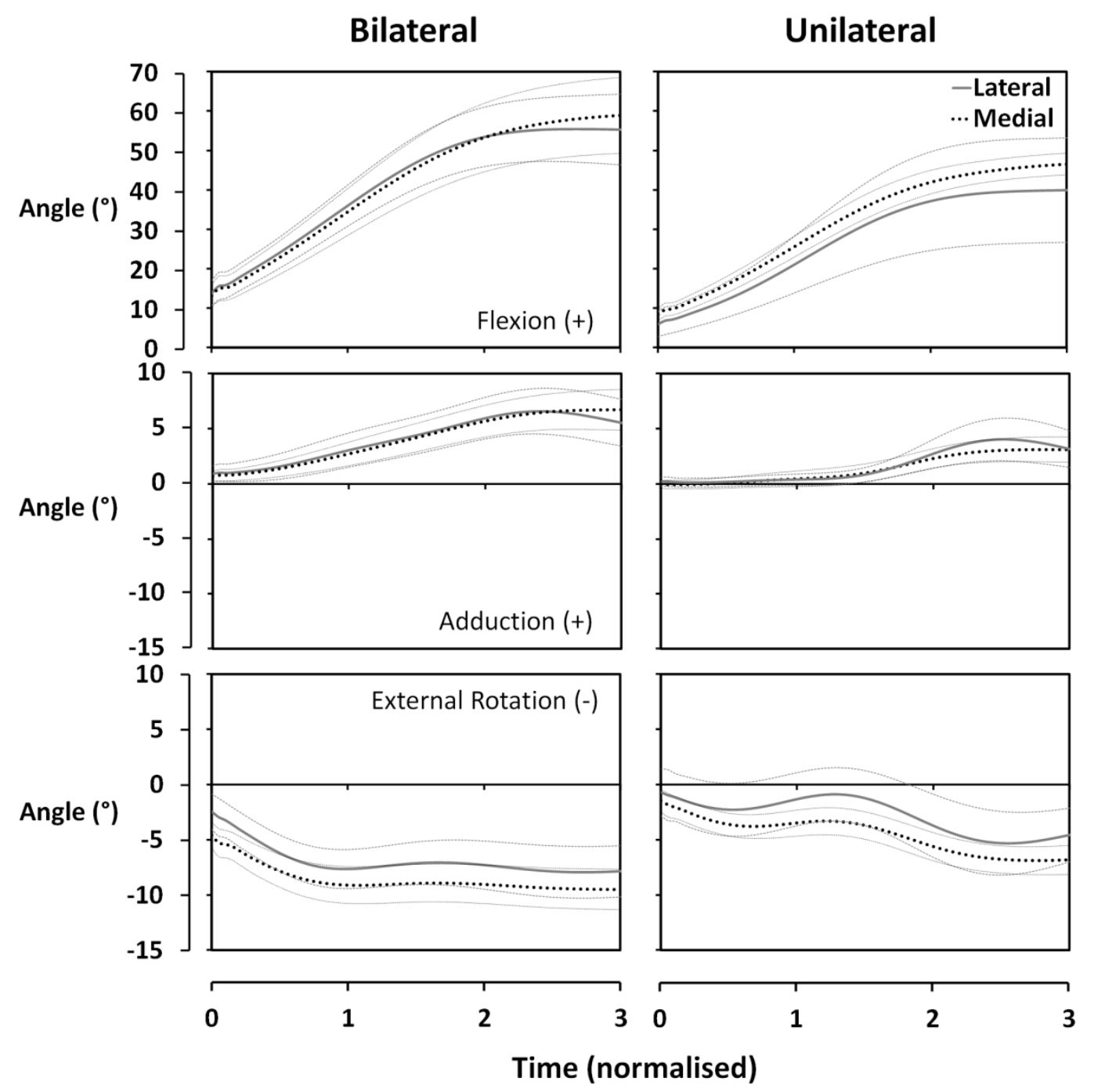

Figure 1

Knee kinematics during bilateral and unilateral landings for medially and laterally loaded participants. Thinner lines indicate the 95\% confidence intervals. 
Bilateral
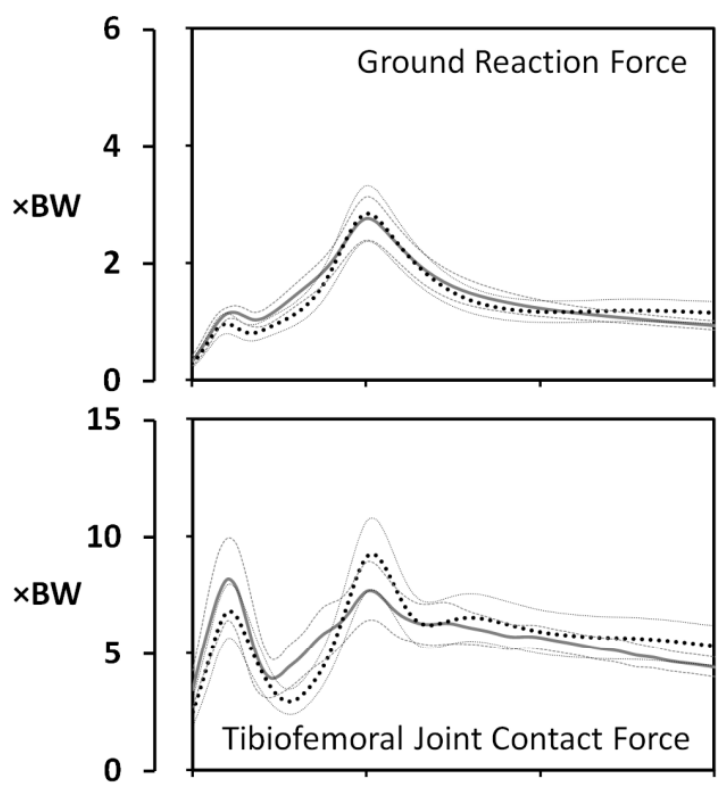

1.00

0.75

0.50

0.25

0.00

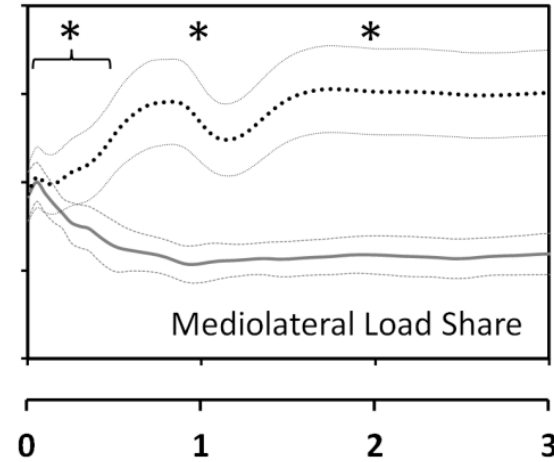

Unilateral
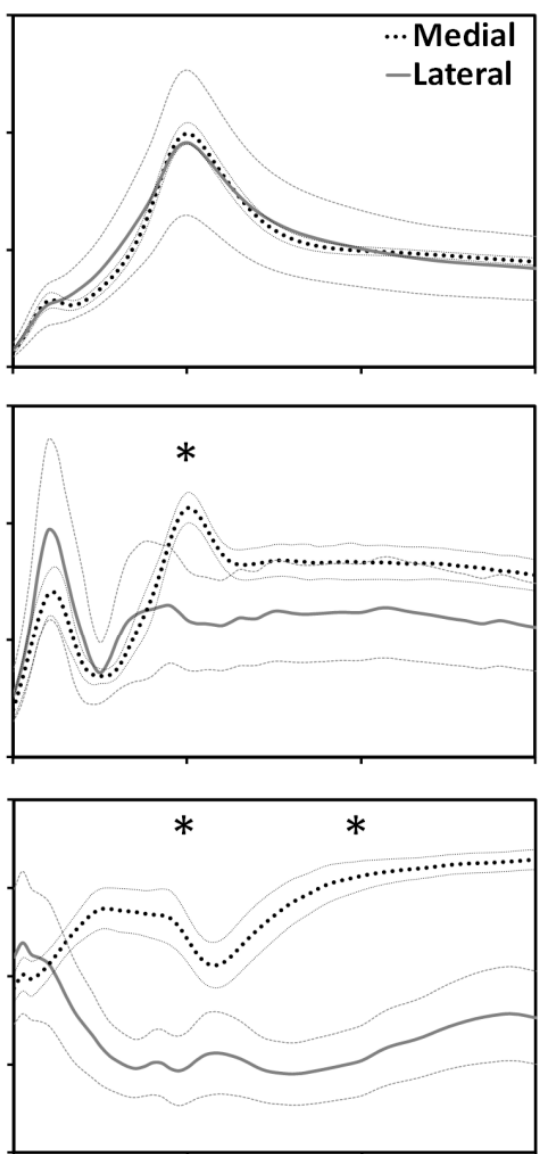

30

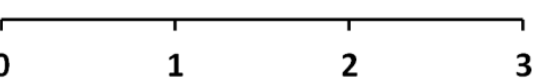

Time (normalised)

Figure 2

Ground reaction force and tibiofemoral joint loading during bilateral and unilateral landings for medially and laterally loaded participants. Thinner lines indicate the $95 \%$ confidence intervals $\left(^{*}=\right.$ significant difference between medial and lateral). 

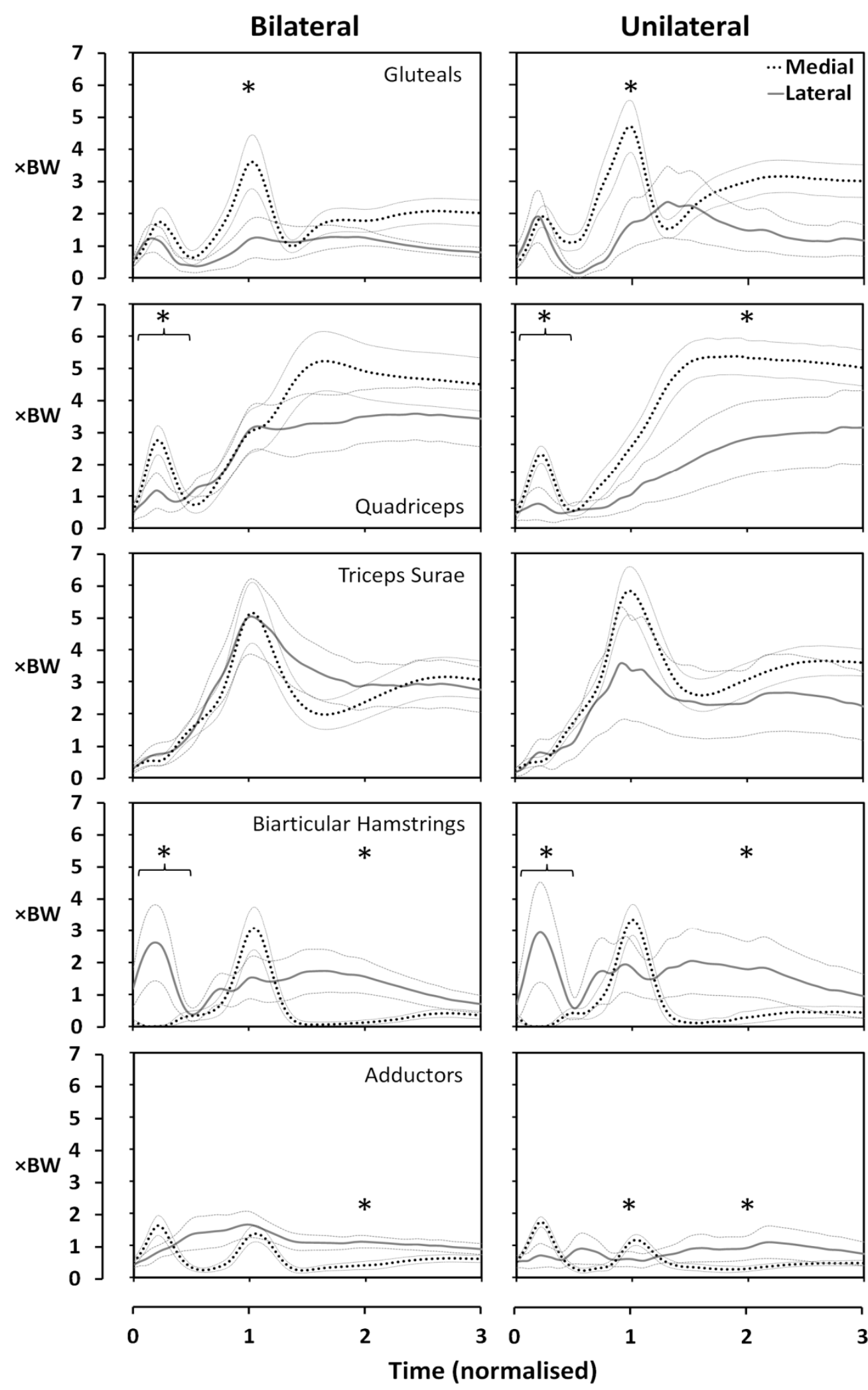

Figure 3

Muscle forces during bilateral and unilateral landings for medially and laterally loaded participants. Thinner lines indicate the $95 \%$ confidence intervals $\left(^{*}=\right.$ significant difference between medial and lateral). 

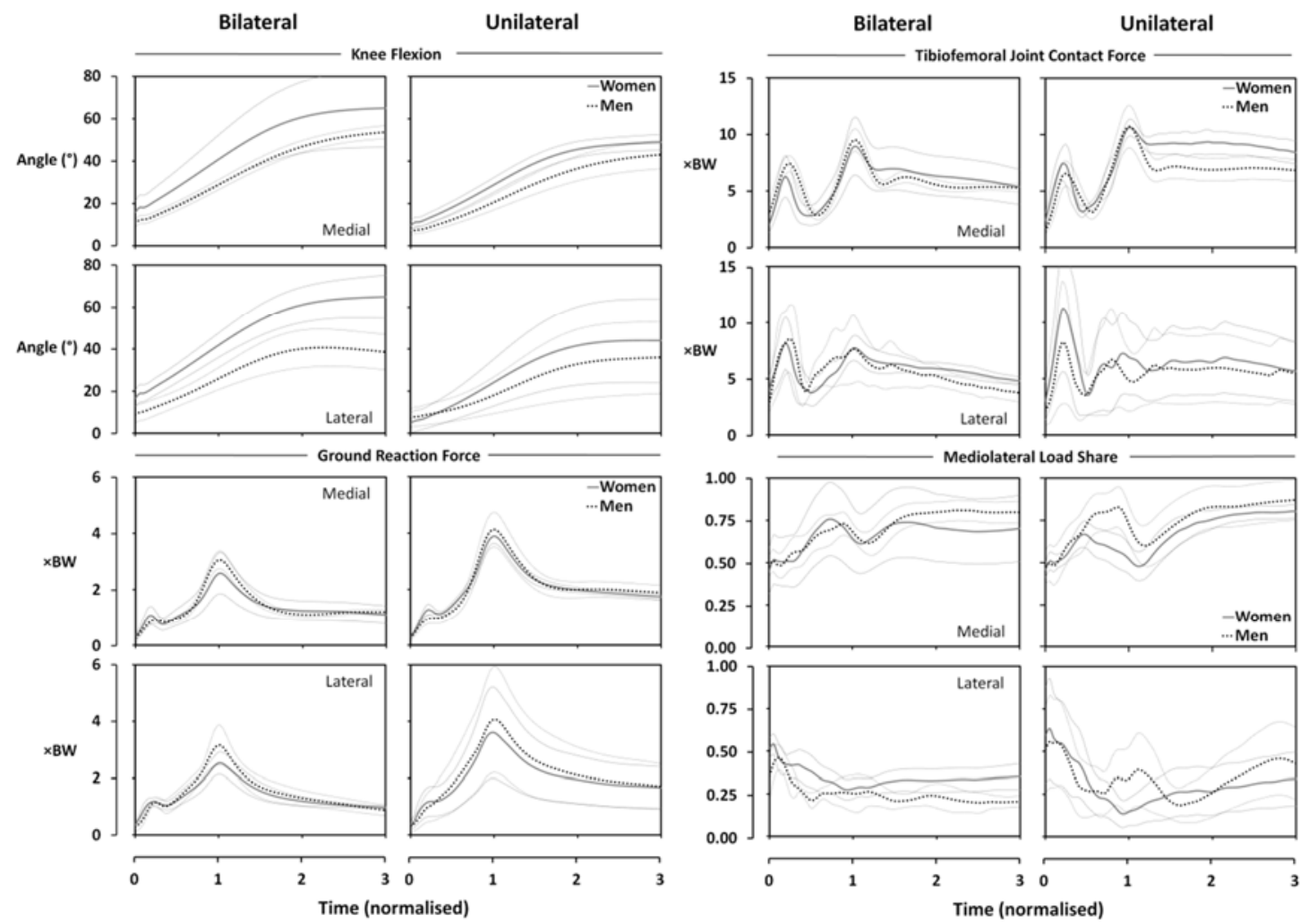

Figure 4

Comparison of the knee flexion angle, ground reaction force, and tibiofemoral joint loading of men and women during landing. Participants are divided into medially and laterally loaded groups and both bilateral and unilateral landings are shown.

Thinner lines indicate the $95 \%$ confidence intervals. 

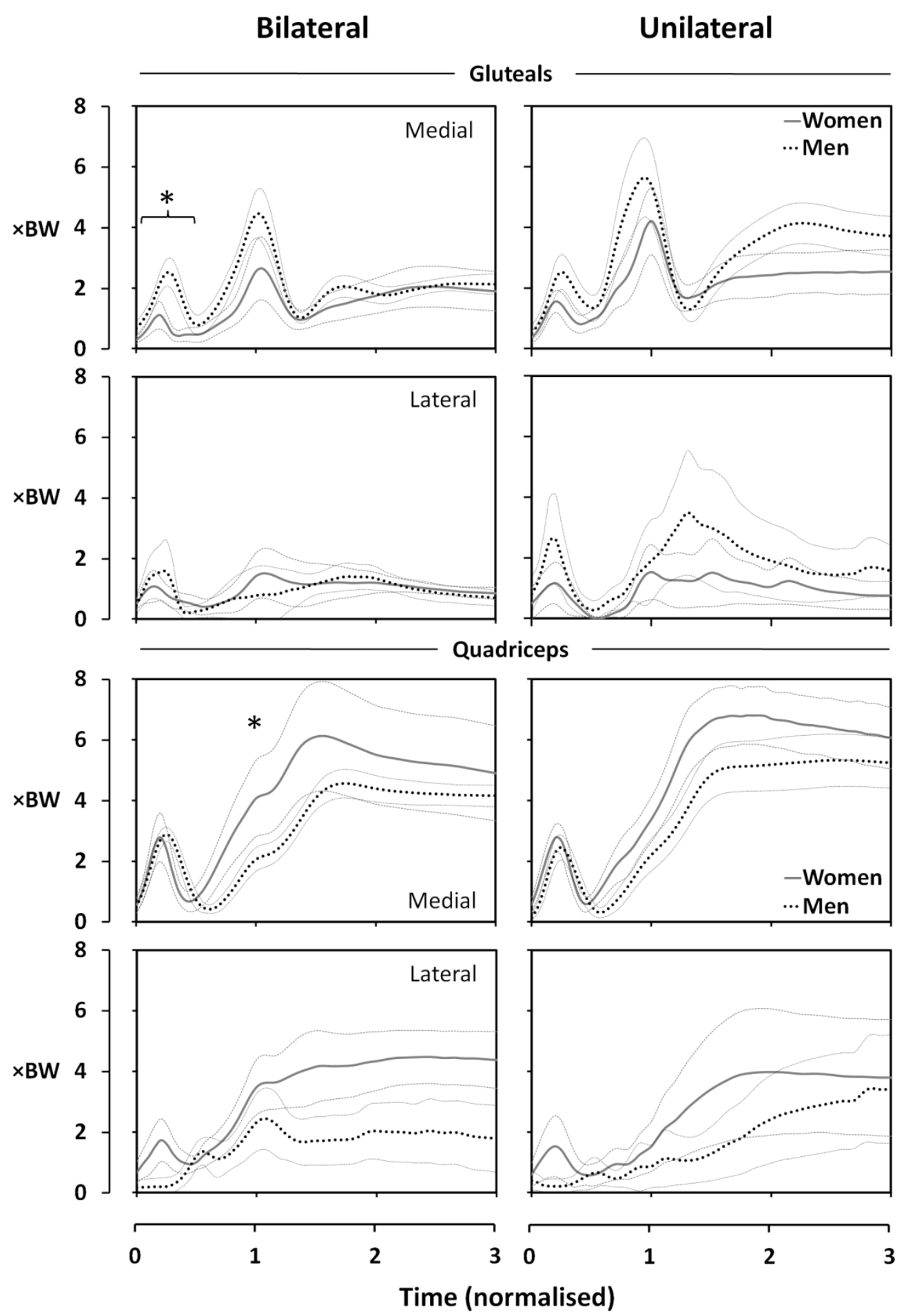

Figure 5

Comparison of gluteal and quadriceps muscle forces for men and women during landing. Participants are separated into medially and laterally loaded groups and both bilateral and unilateral landings are shown. Thinner lines indicate the $95 \%$ confidence intervals $(*=$ significant difference between men and women). 
Bilateral
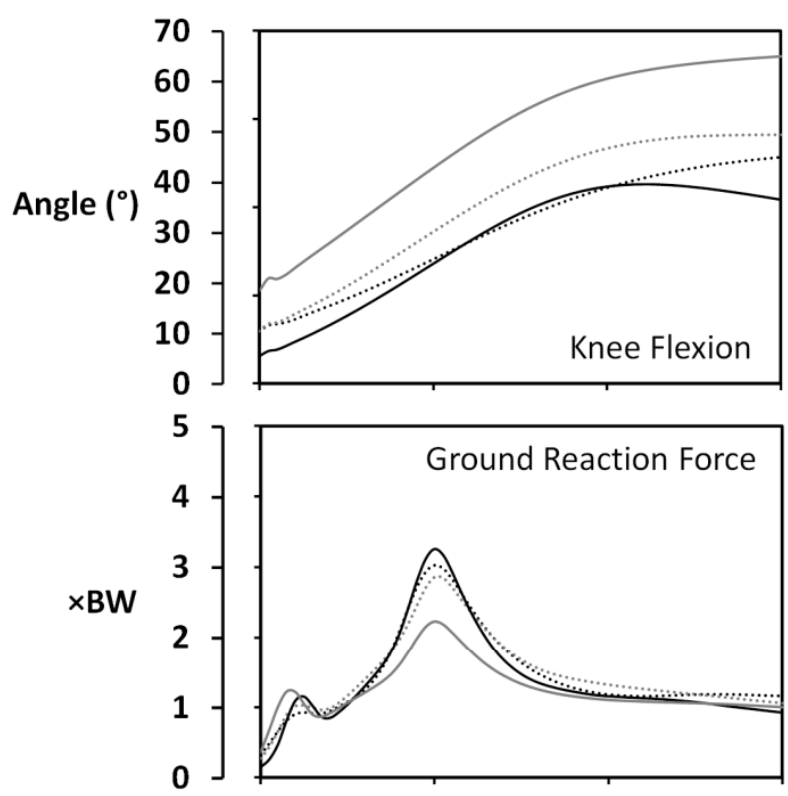

1.0
0.8
0.6
0.4
0.2
0.0

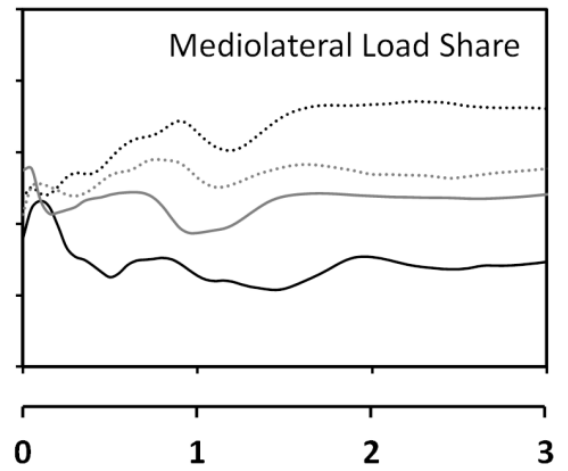

Unilateral
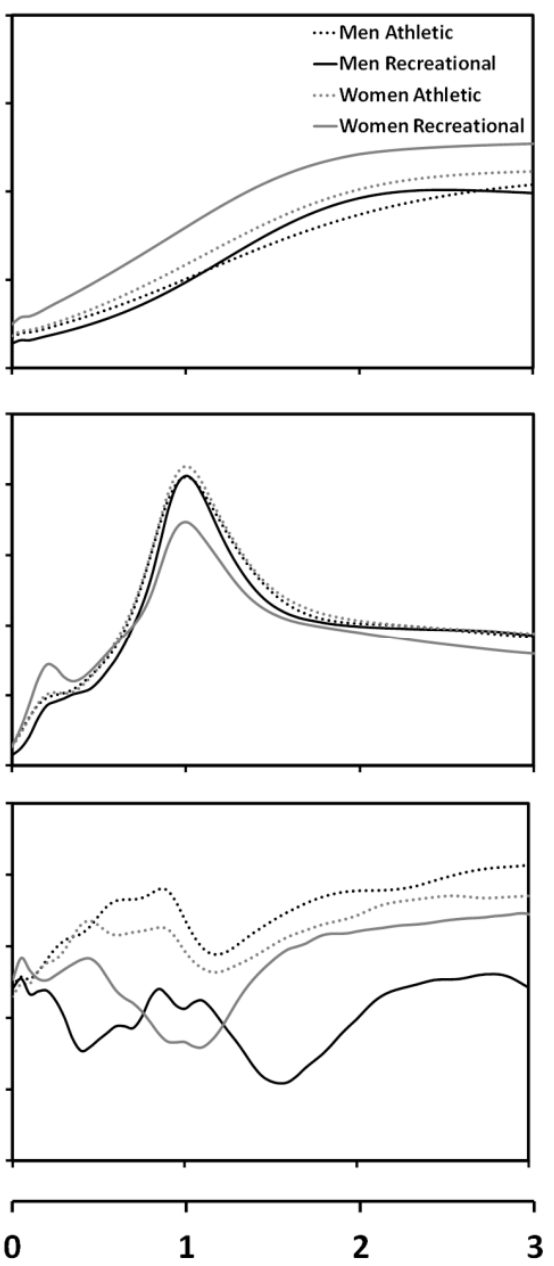

Time (normalised)

\section{Figure 6}

Comparison of the knee flexion angle, ground reaction force and mediolateral load share during bilateral and unilateral landings. Participants are separated by the original recruitment criteria - that is, by gender (men and women) and activity level (athletic and recreational). 


\section{Discussion}

In this study we divided participants into two groups based upon the mediolateral load share exhibited during landing. When divided in this way there was little difference between the two groups in terms of the kinematics of the knee (Figure 1) or the GRF (Figure 2) in either bilateral or unilateral landings. However, despite the very great similarity in the external mechanics of movement, the resulting groups experienced a markedly different pattern of loading of the tibiofemoral joint (Figure 2), with one group being heavily medially loaded and the other equally heavily laterally loaded. Of course, some difference might be expected as the mediolateral share was used as the discriminating factor. However, the size of the difference in conjunction with the number of differences in tibiofemoral joint loading and muscle forces suggest that the mediolateral load share is an effective variable to use to discriminate between differences in landing strategy. This is a significant finding as there is clinical evidence that might suggest that a more laterally loaded knee is a risk factor for ACL injury. For instance, in patients that have experienced an ACL injury it is very common to find a bone bruise in the lateral compartment of the tibial plane (Kaplan et al., 1992; Speer et al., 1992), suggesting that the lateral compartment experiences a greater loading during ACL rupture. It should also be noted that a more laterally loaded knee would be consistent with a valgus knee position, and that a valgus knee position has also been identified as a potential risk factor for ACL injury.

The difference in the mediolateral load share was also commensurate with differences in muscle forces. Most notably, a medially loaded landing strategy involved greater recruitment of the gluteals, biarticular hamstrings and quadriceps (Figure 3). This is consistent with our previous work showing that a lateral to medial shift in TFJ was associated with an increase in gluteal force (Czasche et al., 2018). These data suggest that a medially loaded landing strategy involving greater recruitment of the major muscles of the hip and knee might be protective of the knee during landing (Czasche et al., 2018; Parr et al., 2017).

When men and women with the same landing strategy were compared there were few differences in knee kinematics, GRF or tibiofemoral joint loading (Figure 4). This lends support for the contention that if differences in landing performance between men and women are observed, they should at least in part be characterised as gender rather than sex differences. What is most important is the landing strategy selected which is largely independent of sex (Table 2). In addition, recreational participants were more likely to exhibit a lateral loading pattern during landing, whereas athletic participants were more often medially loaded. This provides some additional support for the idea that a medially loaded landing strategy is more favourable as it is likely the pattern that is adopted by more skilful participants.

One sex difference that is suggested by this study, however, is that within a particular landing strategy, men show greater recruitment of the gluteals and hamstrings, whereas women have a greater use of the quadriceps (Figure 5). These patterns are consistent with previous electromyographic evidence (Chappell et al., 2007; Hart et al., 2007; Nagano et al., 2007; Urabe et al., 2005) and are sometimes suggested to be a factor that could contribute to the higher incidence of ACL injuries in women (Smith et al., 2012). What is notable here is that although there was a different pattern of muscular activity, this did not produce a difference in tibiofemoral loading. However, perhaps this difference in muscular recruitment becomes more of a problem when something goes wrong during a landing.

This study demonstrates the danger in making naive comparisons between men and women. In particular, when men and women were compared without taking account of the landing strategy (time $\times$ gender interaction), there were substantial differences in the external and internal mechanics. However, as seen above, many of these differences disappeared when the landing strategy was taken into account. This might indicate that some of the gender differences that have been reported previously in the literature are at least partially a result of differences in the skill level of the male and female samples studied. The fact that a more risky (laterally loaded) landing strategy is not an inherent sex characteristic and that conclusions are dependent on the samples drawn is reinforced by a consideration of Figure 6 . In this study, the 
recreational men exhibited the most laterally loaded landing strategy despite having similar external mechanics to the athletic men (who were most medially loaded).

A strength of this study is that differences in landing strategy were assessed using a musculoskeletal model that is particularly sensitive to differences in the mediolateral load share (Price et al., 2017). The results of this study demonstrate that there can be large differences in the mediolateral load share without differences in the external mechanics. This finding could explain some of the equivocal results in the literature that were mentioned in the introduction. Similarly this study shows that musculoskeletal models have the potential to be used as clinical tools in the assessment of movement mechanics, in particular by providing additional information that is not available from other approaches.

It should be noted that the model employed in this study was based on a generic model of the musculoskeletal anatomy of the lower limb that was derived from a dissection study of a male cadaver (Klein Horsman et al., 2007). This is appropriate for this study given its focus on the sex/gender dichotomy during landing. In particular, the vast majority of previous studies are based upon the external mechanics of movement and because we used the same generic model here our results are also only a result of differences in the external mechanics. However, previous literature has demonstrated that there are differences in performance of subject-specific and generic models (Cleather and Bull, 2012; Correa et al., 2011; Gerus et al., 2013; Scheys et al., 2008, 2011), and certainly the difference in anatomy between men and women (Kepple et al., 1997) would suggest that a sex-specific musculoskeletal model may be necessary to accurately quantify the sex differences in joint forces during landing. It is entirely possible that the use of sex-specific models of the musculoskeletal anatomy could amplify or ameliorate the sex differences found here, however, the differences due to landing strategy alone should be fairly robust to this factor.

This study provides evidence for a link between a medially loaded landing strategy and greater activation of the musculature of the hip and knee. However such a landing strategy does not necessarily imply differences in the external mechanics of movement. Furthermore, landing strategy rather than sex accounts for greater differences in muscle and joint contact forces during landing, although women may exhibit a greater recruitment of the quadriceps with a lesser recruitment of gluteals and biarticular hamstrings.

\section{References}

Alentorn-Geli E, Myer GD, Silvers HJ, Samitier G, Romero D, Lazora-Haro C, Cugat R. Prevention of noncontact anterior cruciate ligament injuries in soccer players: Part 1: Mechanisms of injury and underlying risk factors. Knee Surg Sports Traumatol Arthrosc, 2009; 17: 705-29

Arendt E, Dick R. Knee injury patterns among men and women in collegiate basketball and soccer: NCAA data and review of literature. Am J Sports Med, 1995; 23(6): 694-701

Beaulieu ML, McLean SG. Sex-dimorphic landing mechanics and their role within the noncontact ACL injury mechanism: evidence, limitations and directions. Sports Med Arthrosc Rehabil Ther Technol SMARTT, 2012; 4: 10

de Britto MA, Carpes FP, Koutras G, Pappas E. Quadriceps and hamstrings prelanding myoelectric activity during landing from different heights among male and female athletes. J Electromyogr Kinesiol, 2014; 24(4): 508-12

Bruton MR, O'Dwyer N, Adams R. Sex differences in the kinematics and neuromuscular control of landing: Biological, environmental and sociocultural factors. J Electromyogr Kinesiol, 2013; 23(4): 747-58

Buchanan TS, Lloyd DG, Manal K, Besier TF. Neuromusculoskeletal modeling: Estimation of muscle forces and joint moments from measurements of neural command. J Appl Biomech, 2004; 20: 367-95

Butler RJ, Willson JD, Fowler D, Queen RM. Gender differences in landing mechanics vary depending on the type of landing. Clin J Sport Med Off J Can Acad Sport Med, 2013; 23(1): 52-7 
Chappell JD, Creighton RA, Giuliani C, Yu B, Garrett WE. Kinematics and electromyography of landing preparation in vertical stop-jump: Risks for noncontact anterior cruciate ligament injury. Am J Sports Med, 2007; 35(2): 235-41

Cleather DJ, Bull AMJ. Influence of inverse dynamics methods on the calculation of inter-segmental moments in vertical jumping and weightlifting. Biomed Eng OnLine, 2010a; 9(1): 74

Cleather DJ, Bull AMJ. Lower-extremity musculoskeletal geometry affects the calculation of patellofemoral forces in vertical jumping and weightlifting. Proc Inst Mech Eng [H], 2010b; 224(9): 1073-83

Cleather DJ, Bull AMJ. An optimization-based simultaneous approach to the determination of muscular, ligamentous, and joint contact forces provides insight into musculoligamentous interaction. Ann Biomed Eng, 2011a; 39(7): 1925-34

Cleather DJ, Bull AMJ. Knee and hip joint forces: Sensitivity to the degrees of freedom classification at the knee. Proc Inst Mech Eng [H], 2011b; 225(6): 621-6

Cleather DJ, Bull AMJ. The development of lower limb musculoskeletal models with clinical relevance is dependent upon the fidelity of the mathematical description of the lower limb. Part 2: patient-specific geometry. Proc Inst Mech Eng [H], 2012; 226(2): 133-45

Cleather DJ, Bull AMJ. The development of a segment-based musculoskeletal model of the lower limb: introducing FreeBody. R Soc Open Sci, 2015; 2(6): 140449

Cleather DJ, Goodwin JE, Bull AMJ. An optimization approach to inverse dynamics provides insight as to the function of the biarticular muscles during vertical jumping. Ann Biomed Eng, 2011a; 39(1): 147-60

Cleather DJ, Goodwin JE, Bull AMJ. Erratum to: An optimization approach to inverse dynamics provides insight as to the function of the biarticular muscles during vertical jumping. Ann Biomed Eng, 2011b; 39: $2476-8$

Correa TA, Baker R, Kerr Graham H, Pandy MG. Accuracy of generic musculoskeletal models in predicting the functional roles of muscles in human gait. J Biomech, 2011; 44(11): 2096-105

Crowninshield RD, Brand RA. A physiologically based criterion of muscle force prediction in locomotion. J Biomech, 1981; 14(11): 793-801

Czasche MB, Goodwin JE, Bull AMJ, Cleather DJ. Effects of an 8-week strength training intervention on tibiofemoral joint loading during landing: a cohort study. BMJ Open Sport Exerc Med, 2018; 4(1): e000273

Damsgaard M, Rasmussen J, Christensen ST, Surma E, de Zee M. Analysis of musculoskeletal systems in the AnyBody Modeling System. Simul Model Pract Theory, 2006; 14(8): 1100-11

Decker MJ, Torry MR, Wyland DJ, Sterett WI, Steadman JR. Gender differences in lower extremity kinematics, kinetics and energy absorption during landing. Clin Biomech, 2003; 18(7): 662-9

Delay BS, Smolinski RJ, Wind WM, Bowman DS. Current practices and opinions in ACL reconstruction and rehabilitation: results of a survey of the American Orthopaedic Society for Sports Medicine. Am J Knee Surg, 2001; 14(2): 85-91

Ding Z, Nolte D, Kit Tsang C, Cleather DJ, Kedgley AE, Bull AMJ. In vivo knee contact force prediction using patient-specific musculoskeletal geometry in a segment-based computational model. J Biomech Eng, 2016; 138(2): 021018-021018

D'Lima DD, Fregly BJ, Patil S, Steklov N, Colwell CW. Knee joint forces: Prediction, measurement, and significance. Proc Inst Mech Eng [H], 2012; 226(2): 95-102

Elliot DL, Goldberg L, Kuehl KS. Young women's anterior cruciate ligament injuries: An expanded model and prevention paradigm. Sports Med, 2010; 40: 367-76

Erdemir A, McLean S, Herzog W, van den Bogert AJ. Model-based estimation of muscle forces exerted during movements. Clin Biomech, 2007; 22: 131-54

Fagenbaum R, Darling WG. Jump landing strategies in male and female college athletes and the implications of such strategies for anterior cruciate ligament injury. Am J Sports Med, 2003; 31(2): 233-40

Ferretti A, Papandrea P, Conteduca F, Mariani PP. Knee ligament injuries in volleyball players. Am J Sports Med, 1992; 20: 203-7 
Fleming BC, Beynnon BD. In vivo measurement of ligament/tendon strains and forces: A review. Ann Biomed Eng, 2004; 32(3): 318-28

Ford KR, Myer GD, Smith RL, Vianello RM, Seiwert SL, Hewett TE. A comparison of dynamic coronal plane excursion between matched male and female athletes when performing single leg landings. Clin Biomech, 2006; 21(1): 33-40

Ford KR, Shapiro R, Myer GD, Van Den Bogert AJ, Hewett TE. Longitudinal sex differences during landing in knee abduction in young athletes. Med Sci Sports Exerc, 2010; 42(10): 1923-31

Gehring D, Melnyk M, Gollhofer A. Gender and fatigue have influence on knee joint control strategies during landing. Clin Biomech, 2009; 24(1): 82-7

Gerus P, Sartori M, Besier TF, Fregly BJ, Delp SL, Banks SA, Pandy MG, D'Lima DD, Lloyd DG. Subjectspecific knee joint geometry improves predictions of medial tibiofemoral contact forces. $J$ Biomech, 2013; 46(16): 2778-86

Golas A, Wilk M, Statsny P, Maszczyk A, Pajerska K, Zajac A. Optimizing Half Squat Post Activation Potential Load In Squat Jump Training For Eliciting Relative Maximal Power In Ski Jumpers. J Strength Cond Res, 2017; doi: 10.1519/JSC.0000000000001917 [Epub ahead of print]

Hart JM, Garrison JC, Kerrigan DC, Palmieri-Smith R, Ingersoll CD. Gender differences in gluteus medius muscle activity exist in soccer players performing a forward jump. Res Sports Med Print, 2007; 15(2): $147-55$

Hewett TE. Neuromuscular and hormonal factors associated with knee injuries in female athletes: Strategies for intervention. Sports Med, 2000; 29: 313-27

Hughes G, Watkins J. A risk-factor model for anterior cruciate ligament injury. Sports Med, 2006; 36: 411-28

Kaplan PA, Walker CW, Kilcoyne RF, Brown DE, Tusek D, Dussault RG. Occult fracture patterns of the knee associated with anterior cruciate ligament tears: Assessment with MR imaging. Radiology, 1992; 183(3): 835-8

Kepple TM, Sommer III HJ, Siegel KL, Stanhope SJ. A three-dimensional musculoskeletal database for the lower extremities. J Biomech, 1997; 31(1): 77-80

Kernozek TW, Torry MR, VAN Hoof H, Cowley H, Tanner S. Gender differences in frontal and sagittal plane biomechanics during drop landings. Med Sci Sports Exerc, 2005; 37(6): 1003-12

Kiriyama S, Sato H, Takahira N. Gender differences in rotation of the shank during single-legged drop landing and its relation to rotational muscle strength of the knee. Am J Sports Med, 2008; 37(1): 168-74

Klein Horsman MD, Koopman HFJM, van der Helm FCT, Poliacu Prose L, Veeger HEJ. Morphological muscle and joint parameters for musculoskeletal modelling of the lower extremity. Clin Biomech, 2007; 22: $239-47$

Lephart SM, Ferris CM, Riemann BL, Myers JB, Fu FH. Gender differences in strength and lower extremity kinematics during landing. Clin Orthop, 2002; 401: 162-169

Lohmander LS, Englund PM, Dahl LL, Roos EM. The Long-term Consequence of Anterior Cruciate Ligament and Meniscus Injuries Osteoarthritis. Am J Sports Med, 2007; 35(10): 1756-69

Louboutin H, Debarge R, Richou J, Selmi TAS, Donell ST, Neyret P, Dubrana F. Osteoarthritis in patients with anterior cruciate ligament rupture: A review of risk factors. The Knee, 2009; 16(4): 239-44

Malinzak RA, Colby SM, Kirkendall DT, Yu B, Garrett WE. A comparison of knee joint motion patterns between men and women in selected athletic tasks. Clin Biomech, 2001; 16(5): 438-45

Nagano Y, Ida H, Akai M, Fukubayashi T. Gender differences in knee kinematics and muscle activity during single limb drop landing. The Knee, 2007; 14(3): 218-23

Norcross MF, Lewek MD, Padua DA, Shultz SJ, Weinhold PS, Blackburn JT. Lower extremity energy absorption and biomechanics during landing, part II: frontal-plane energy analyses and interplanar relationships. J Athl Train, 2013; 48(6): 757-63

Orishimo KF, Liederbach M, Kremenic IJ, Hagins M, Pappas E. Comparison of landing biomechanics between male and female dancers and athletes, Part 1 influence of sex on risk of anterior cruciate ligament injury. Am J Sports Med, 2014; 42(5): 1082-8

Pandy MG. Computer modeling and simulation of human movement. Annu Rev Biomed Eng, 2001; 3: 245-73

(C) Editorial Committee of Journal of Human Kinetics 
Pappas E, Hagins M, Sheikhzadeh A, Nordin M, Rose D. Biomechanical Differences Between Unilateral and Bilateral Landings From a Jump: Gender Differences: Clin J Sport Med, 2007; 17(4): 263-8

Parr M, Price PD, Cleather DJ. Effect of a gluteal activation warm-up on explosive exercise performance. BMJ Open Sport Exerc Med, 2017; 3(1): e000245

Price PDB, Gissane C, Cleather DJ. Reliability and minimal detectable change values for predictions of knee forces during gait and stair ascent derived from the FreeBody musculoskeletal model of the lower limb. Front Bioeng Biotechnol, 2017; 5: 74

Prodromos CC, Han Y, Rogowski J, Joyce B, Shi K. A meta-analysis of the incidence of anterior cruciate ligament tears as a function of gender, sport, and a knee injury-reduction regimen. Arthrosc J Arthrosc Relat Surg, 2007; 23(12): 1320-1325.e6

Raikova RT. Investigation of the influence of the elbow joint reaction on the predicted muscle forces using different optimization functions. J Musculoskelet Res, 2009; 12: 31-43

Ristić V, Ninković S, Harhaji V, Milankov M. Causes of anterior cruciate ligament injuries. Med Pregl, 2010; 63(7-8): 541-5

Roos EM. Joint injury causes knee osteoarthritis in young adults. Curr Opin Rheumatol, 2005; 17: 195-200

Scheys L, Desloovere K, Suetens P, Jonkers I. Level of subject-specific detail in musculoskeletal models affects hip moment arm length calculation during gait in pediatric subjects with increased femoral anteversion. J Biomech, 2011; 44: 1346-53

Scheys L, Spaepen A, Suetens P, Jonkers I. Calculated moment-arm and muscle-tendon lengths during gait differ substantially using MR based versus rescaled generic lower-limb musculoskeletal models. Gait Posture, 2008; 28(4): 640-8

Schmitz RJ, Kulas AS, Perrin DH, Riemann BL, Shultz SJ. Sex differences in lower extremity biomechanics during single leg landings. Clin Biomech, 2007; 22(6): 681-8

Shimokochi Y, Shultz SJ. Mechanisms of noncontact anterior cruciate ligament injury. J Athl Train, 2008; 43: $396-408$

Smith HC, Vacek P, Johnson RJ, Slauterbeck JR, Hashemi J, Shultz S, Beynnon BD. Risk Factors for Anterior Cruciate Ligament Injury. Sports Health, 2012; 4(1): 69-78

Southgate DF, Cleather DJ, Weinert-Aplin RA, Bull AM. The sensitivity of a lower limb model to axial rotation offsets and muscle bounds at the knee. Proc Inst Mech Eng [H], 2012; 226(9): 660-9

Speer KP, Spritzer CE, Bassett FH, Feagin JA, Garrett WE. Osseous injury associated with acute tears of the anterior cruciate ligament. Am J Sports Med, 1992; 20(4): 382-9

Urabe Y, Kobayashi R, Sumida S, Tanaka K, Yoshida N, Nishiwaki GA, Tsutsumi E, Ochi M. Electromyographic analysis of the knee during jump landing in male and female athletes. The Knee, 2005; 12(2): 129-34

Van Sint Jan S. Skeletal landmark definitions: Guidelines for accurate and reproducible palpation. University of Brussels, Department of Anatomy: Belgium (www.ulb.ac.be/ anatemb); 2005

\section{Corresponding author:}

\section{Daniel Cleather}

Faculty of Sport, Health and Applied Sciences,

St. Mary's University, Twickenham, UK.

Phone: +420 775255586

E-mail: daniel.cleather@stmarys.ac.uk 